\title{
EL REFRENDO MINISTERIAL DURANTE LA SEGUNDA REPUBLICA. DOS EPISODIOS CONFLICTIVOS
}

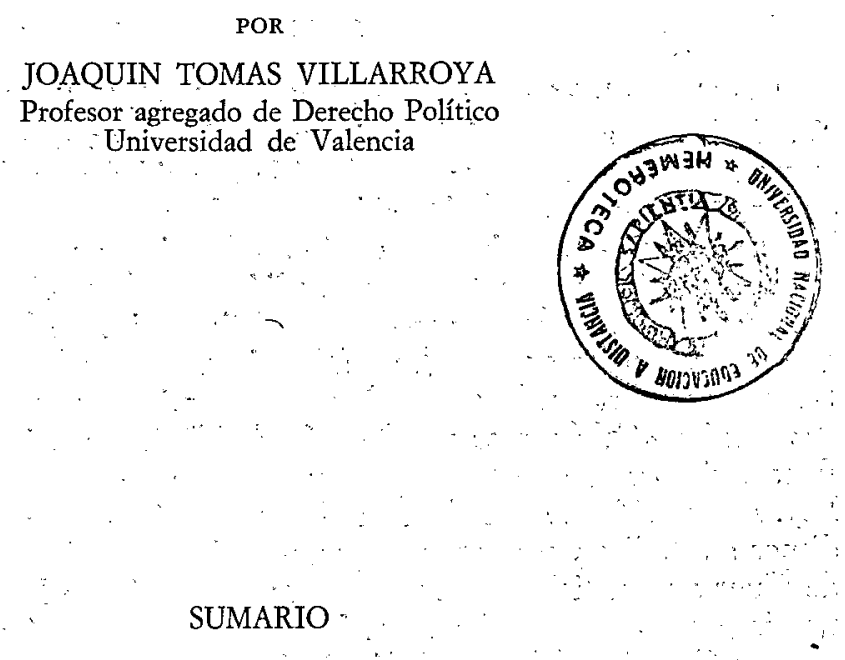

I. INTRODUcción.-II. LA LEY DE AMNISTÍA: 1. Necesidad o no de refrëndo ministerial al veto presidencial. 2. Naturaleza del escrito presidencial. 3. Valor constitucional del escrito presidencial.-III. LA DISOLUcIóN DE LAS CORTES: 1. La redacción. 2. El refrendo. 3. La retractación.

\section{INTRODUCCION}

El artículo 84 de la Constitución de 1931 decía: «Serán nulos y. sin fuerza alguna de obligar los actos y mandatos del Presidente que no estén refrendados por un Ministro. La ejecución de dichos mandatos implicará responsabilidad penal. Los Ministros que refrenden actos o mandatos del Presidente de la República asumen la plena responsabilidad política y civil y participan de la criminal que de ellos pueda derivarse.» El profesor Pérez Serrano, en 1932, después de manifestar su conformidad de principio con la tesis del artículo, preguntaba: «... ¿no hay excepciones a la regla general, pudiendo contarse entre ellas desde luego la interposición del'veto y debiendo acaso incluirse también la disolución de Cortes...? " ${ }^{1}$. De esta manera, el primer comentarista de la Constitución parecía anticipar - con su finura habitual- dos grandes problemas que el refrendo plantearía: el uno, en 1934, con ocasión del propósito del Presidente de la República de devolver a las Cortes la Ley de Amnistía votada por las mismas; el segundo, en 1936, cuando se trató de determinar si la disolución de las Constituyentes debía entrar o no en el cómputo a que se refería el artículo 81 y que, a la postre, llevó a la destitución de Alcalá-Zamora de la Presidencia de la República. Estos temas, sumamente conflictivos y que tuvieron gran influencia en la vida de la segunda República merecen atención detenida y' separada.

${ }^{1}$ Pérez Serrano, La Constitución española, Madrid, 1932, pág. 273. 


\section{LA LEY DE AMNISTIA}

Las Cortes habían aprobado el día 20 de abril de 1934 , la Ley de Amnistía. El día 23 se celebró Consejo de Ministros en el que el Jefe del Estado opuso reparos a la misma; manifestó la necesidad de reformarla; declaró que, en los términos en que había sido aprobada, no estaba dispuesto a promulgarla. En el mismo Consejo se produjo un forcejeo entre el Presidente de la República y el Gobierno; Lerroux accedió a que la publicación de la Ley fuese acompañada de la de Decretos de los Ministerios de la Guerra y de Justicia que recogiesen las sugerencias del Presidente de la República y que interpretasen y completasen la misma ley en el sentido propuesto por éste. Lerroux testimonia: «Celebramos un Consejo de Ministros bajo la presidencia de $\mathrm{Su}$ Excelencia, en el que trató de convencernos de la necesidad de rectificar la Ley. Pronunció un largo discurso. No consiguió otro resultado que el de decidirnos a estudiar y proponer proyectos de Decreto dictados por los Ministerios de Guerra y Justicia, que regulasen la aplicación de la amnistía e impidiesen una interpretación abusiva.... ${ }^{2}$. La discusión continuó de manera más aguda en otro Consejo celebrado al día siguiente: al parecer, en el curso del mismo, Alcalá-Zamora manifestó que los Decretos aclaratorios no eran suficientes y reiteró, decididamente su voluntad de pedir al Congreso, en mensaje motivado, una nueva delibéración sobre la ley ${ }^{3}$. Salazar Alonso, Ministro del Gobierno, nos dejaría, poco después, referencia precisa y directa de este Consejo del día 24: «El Consejo de Ministros — refiere- estimó que no podía aconsejar a Su Excelencia dicha devolución y así se lo hizo saber después de un largo discurso del Presidente, en el cual expuso su preocupación; más aún: su tortura... Nos dijo que estaba verdaderamente febril. Tuvo alusiones para todos; hizo con el estilo en él peculiar excursiones a otros asuntos; recordó detalles, a veces minúsculos; subió a las cumbres de la filosofía política y descendió a recuerdos personales, con todo el relieve, eso sí, que da siempre a lo personal y episódico... Discurso dramático en verdad... Tuvo frases mortificantes para quienes votaron la Ley y para el Gobierno que no había sabido vigilar su redacción... Acreditó, como tantas otras veces, su enemiga al Parlamento actual, al que ha calificado de peor que las Constituyentes... ${ }^{4}$.

Ahora bien: dejando aparte las razones de Alcalá y los términos serenos o apasionados en que se expresara, su pretensión tropezaba, ante la actitud del Gobierno, con una dificultad esencial: el Jefe del Estado, de conformidad con el artículo 83 de la Constitución, tenía la facultad de pedir, en mensaje razonado, nueva deliberación al Congreso; pero el artículo 84 exigía que los actos y mandatos del Presidente de la República estuviesen refrendados por un Ministro. Alcalá, en el Cónsejo del 24, se encontró con la negativa cortés y silenciosa de todos los Ministros a refrendar su decisión: «Como no advertía en ninguno de los Ministros - referiría luego Lerroux-, disposición favora-

${ }^{2}$ Lerroux, La pequeña bistoria, pág. 249.

3 Lerroux, op. cit., pág. 250.

4 Salazar Alonso, Bajo el signo de la revolución, Madrid, 1935, pág. 88. De nuevo es necesario remitirse a la obra de Lerroux en págs. 250 y sigs: 
ble a sus deseos, apeló al recurso de interpelarles; a todos o casi todos, uno por uno. Lo que buscaba no era ya un acuerdo del Consejo, sino la firma, la firma de un Ministro que, en cumplimiento del artículo 84 de la Constitución, refrendase el Decreto de devolución al Congreso...» ${ }^{5}$. Ningún Ministro se prestó. Después de forcejeos e incidencias que aquí tienen un interés secundario, el Presidente firmó la Ley y los.Decretos aclaratorios de que se ha hecho mención: el Gobierno consideró concluido el problema. Pero no fue así; al con:trario, lo grave comenzó precisamente en aquel momento. El Presidente de la República remitió al de las Cortes el texto de la Ley debidamente firmado, pero acompañado de un largo escrito -que pretendía ser fórmula de promulgación- sin refrendo alguno, en el que exponía sus escrúpulos jurídicos en relación a la Ley de Amnistía y señalaba que ésta alteraba de manera dudosamente regular diversas normas del ordenamiento jurídico con grave daño del mismo. Los argumentos y observaciones de Alcalá quizá eran atendibles; pero el modo de expresarlos quebrantaba gravemente la ley fundamental de la República y dañaba directamente las instituciones del régimen: la Presidencia de la República quedaba en entredicho; el Gobierno, desautorizado; el Congreso, desairado y rebajado. En todo caso, la nota de Alcalá produjo una singular conmoción y dejó planteados graves problemas constitucionales que adquirieron, rápidaménte, estado parlamentario ${ }^{6}$.

El primer problema consistía en determinar si el veto presidencial necesitaba o no refrendo ministerial. La redacción, precisa y rotunda, del artículo 84 parecía no admitir excepción. Con todo, conviene recordar que, en la discusión constituyente, Altabas preguntó si la interposición del veto presidencial había de estar refrendado por un Ministro; Villanueva, miembro de la Comisión de la Constitución, contestó negativamente; pero Jiménez de Asús, presidente de aquella Comisión, al trazar, poco tiempo después, el proceso de formación de la Constitución, consideraba que no podía existir semejante excepción ${ }^{7}$. Ahora, con ocasión del grave episodio de la Ley de Amnistía, el problema se planteaba crudamente ${ }^{8}$. En esta ocasión, Gil-Robles sostuvo el criterio -comparti-

${ }^{5}$ Lerroux, op. cit., pág. 250.

- Plá escribe que el día 24 de abril de 1934, a las seis y media de la tarde, «se presentó ren el Congreso, con una misión especial, el secretario general de la Presidencia de la República, señor Sánchez Guerra. Se creyó, en principio, que dicho señor venía a entregar al presidente de la Cámara, promulgada, la ley de amnistía para ser archivada, como es costumbre. De todos modos, sorprendió que fuera el propio secretario general de la Casa el encargado de esta misión. Se supo enseguida que el señor Alcalá-Zamora había promulgado la ley, pero que, además, había mandado un documento - - dos pliegos a máquina- conteniendo las reservas puestas por Su Excelencia al trámite de la promulgación. Esto produjo la natural emoción y una expectación sin precedentes. El conflicto entre el presidente de la República y el del Parlamento se abría con todas sus consecuencias...) (Historia de la II República española, III, pág. 165). Por su parte, Fernández Almagro advierte que la nota presidencial recordaba la «coletilla» de Fernando VII durante el trienio liberal (Historia de la República española, 1940, pág. 99).

7 Jiménez de Asúa, Proceso bistórico de la Constitución de la República española, 1932, página 382. El testimonio de Asúa sería recordado por Samper en la discusión parlamentaria que siguió a la remisión de la nota (Diario de Sesiones, 2 de mayo de 1934, pág. 2530).

${ }^{8}$ El profesor Pérez Serrano después del episodio se ocupó del tema en un estudio singularmente valioso: «Cuestión práctica: ¿Necesita refrendo el veto presidencial», en $R e$ vista de Derecbo Público, marzo, 1935, pág. 84. 
do de manera general- de que el veto presidencial necesitaba del refrendo ministerial porque siendo el Presidente de la República políticamente irresponsable ante el Parlamento era necesario que un Ministro asumiera la oportuna responsabilidad; porque el artículo 84 de la Constitución no establecía excepción alguna; y porque, de admitirse la tesis contraria, podría llegarse a la consecuencia «de que el Presidente de la República, de acuerdo con la tercera parte más uno de los miembros de la Cámara, hiciera totalmente inútil la labor de los otros dos tercios que representaban la mayoría que apoya a un Gobierno.... ${ }^{9}$. Por su parte, Azaña, en la misma discusión, afirmaba también la necesidad del refrendo ministerial para el veto presidencial; pero, dando un paso más, juzgaba que, en tal ocasión, aquel refrendo era, por parte del Gobierno, debido y obligado: si no se admitía tal tesis, resultaría que «las prerogativas del Presidente de la República a quien se transfieren es al presidente del Consejo de Ministros y al Gobierno y eso es lo que no ha querido la Constitución...» ${ }^{10}$. En suma: en la discusión que estamos examinando, se entendió que el veto exigía refrendo; pero que tal exigencia era un defecto de la Constitución que quizá convendría corregir. De ahí que la Ley de Amnistía, en este punto concreto, dejase recuerdo y huella posterior. En este sentido, la exposición previa de reforma constitucional de 1935 decía: «El veto debe entenderse que es independiente del refrendo, que no debe exigirse en el caso de atribuciones privativas del Presidente de la República»" ${ }^{11}$. Y en este mismo sentido, Alcalá, poco después de su destitución, escribía: «El veto es del Presidente de la República y no puede ser del Gobierno, porque es lo primero lo que dice inequivocadamente el artículo 83; porque el Gobierno sería absurdo que reservara sus razonamientos para un mensaje posterior a la ley, cuando pudo alegarlos antes de que ésta se votara, puesto inconfundible con el alejamiento del Jefe del Estado, que no puede mezclarse en una deliberación parlamentaria, mientras ésta se halle en curso; porque, en régimen parlamentario, o el Gobierno cuenta con la mayoría y entonces la ley saldría a su gusto, haciendo innecesario su veto, o es vencido por aquélla y cae, sin poder interponerlo...» ${ }^{12}$. Tales afirmaciones y observaciones podrían ser atinadas; pero cuando las Cortes del 34 discutieron el problema creado por la Ley de Amnistía, se entendió, de manera general, que el veto presidencial requería refrendo., ministerial.

El segundo problema consistía en determinar la naturaleza del escrito o nota presidencial. Alcalá-Zamora, en la misma nota, trataba de precisar esta naturaleza, señalando que, de una parte, era una forma de promulgación; de otra, una explicación que juzgaba deber a las Cortes y a la opinión. Cada una de estas afirmaciones merece un examen separado. Por de pronto, el Presidente de la República trataba de justificar su actuación alegando que «el artículo 83 de la Constitución no impone fórmula inalterable para autori-

- Diario de Sesiones, 2 de mayo de 1934, pág. 2538.

${ }^{10}$ Diario de Sesiones, 2 de mayo de 1934, pág. 2545. El mismo Azaña entendía que el Gobierno, con su actitud, había secuestrado la prerrogativa presidencial.

${ }^{11}$ El texto del proyecto en Sevilla Andrés, Constituciones y otras leyes y proyectos políticos de España, II, 1969, pág. 323.

${ }_{12}$ Alcalá-Zamora, Los defectos de la Constitución de 1931, Madrid, 1936, pág. 180. 
zar la promulgación de las leyes, y al amparo de esa justificada holgura no ha sido siempre igual la que se ha empleado...» Ciertamente, la Constitución dejaba latitud suficiente en orden a la fórmula de promulgación; pero las consecuencias que el Presidente pretendía extraer y extrajo de tal latitud podían estimarse exageradas y se prestaban a interpretaciones varias. Por de pronto - -yá entonces se señaló donosamente - parecía evidente que era tan ajena a la idea de los autores de la Constitución «la posibilidad de que la promulgación se 'trocase en un índice de inquietudes espirituales o en un sobradero de conocimientos jurídicos como de que apareciese respaldada con un delicado madrigal...» Pero, además, resultaba, asimismo, anómalo que se utilizase -lo advirtió Goicoechea - la fórmula de promulgación como medio de consumir un turno en contra de una ley examinada y aprobada por el Parlamento: la autoridad de la ley y la de los encargados de aplicarla quedaba seriamente deteriorada desde el momento en que el-Jefe del Estado utilizaba la fórmula de promulgación para poner de manifiesto los defectos de aquélla y debilitaba el influjo que toda norma debe proyectar y ejercer en el ánimo de los ciudadanos ${ }^{13}$. Más todavía: la nota presidencial, al recordar que no siempre se había utilizado la misma fórmula de promulgación, se refería, sin mencionarla, a la Ley de Congregaciones: en ésta, tal fórmula, aunque distinta de la habitual, era muy breve y pretendía únicamente apuntar que el Jefe del Estado, conforme o no con aquélla, procedía a su promulgación en virtud de un supuesto automatismo en la aplicación de los preceptos constitucionales; pero difícilmente podía admitir parangón con la extensión, la meticulosidad y la aparatosidad que ofrecía la larga nota presidencial a la Ley de Amnistía. En fin, el Presidente de la República, en la misma nota, reconocía que «la previsión fundada, lindante con la evidencia, sin necesidad de exploración, patentiza la inclinación de las Cortes, en contacto inmediato y con origen reciente, respecto de la opinión pública, a mantener el texto votado, y no por una explicable y legítima defensa de potestad que nadie discute ni combate, sino, porque al reflexionar sobre ello, estimaría más conveniente al interés nacional sustentado...»: si era así, parecía sorprendente que por un medio dudosamente regular, el Jefe del Estado utilizase algo tan delicado como la fórmula de promulgación de una ley para exponer un criterio opuesto a la voluntad. nacional.

De otra parte, el Presidente de la República trataba de dibujar la naturaleza de su nota como una explicación al Parlamento y a la opinión: el artículo 83 de la Constitución - decía en la misma nota- «que exige el razonamiento expreso cuando el Presidente de la República se decida a pedir segunda deliberación a las. Cortes no excluye parecida explicación cuando el Jefe del Estado se abstenga de ejercitar la prerrogativa. Permitida, por tanto, la explicación, es cónveniente en los casos arduos y conforme a la esencia del régimen, ya que la República y la democracia, para ser renovación de costumbres, y no. sólo de textos, suponen que a las Cortes, primero, a la opinión después, se le: hablen como tiene derecho a ella, expresando la verdad entera de los hechos. y la sinceridad plena en los estados de conciencia...» Pero semejante argu-

${ }^{13}$ Diario de Sesiones, 2 de mayo de 1934, pág. 2520. 
mentación parecía artificiosa, rebuscada y de dudosa exactitud. En este sentido, conviene señalar que el artículo 83 preveía solamente los dos supuestos de que el Presidente de la República promulgase las leyes o las devolviese al Congreso para nueva deliberación; la tercera vía utilizada por el Presidente, firmando y oponiendo reparos, no aparecía prevista en aquel artículo, y, por tanto, su regularidad resultaba, al menos, dudosa y discutible. Pero, además, la tesis de que la más alta magistratura de la nación podía o debía explicar —en la promulgación de las leyes - hechos objetivos o estados de conciencia podía llevar, en ocasiones, a penosas situaciones en el orden político y aún en el meramente personal. En la línea de este pensamiento, Prieto, en la discusión parlamentaria del episodio, advirtió que los argumentos de fondo expuestos por el Jefe del Estado en su documento coincidían, en medida considerable, con las objeciones que los socialistas habían opuesto y oponían a la Ley de Amnistía; pero entendía que si aquél, por razones políticas o de otro orden, no podía o no quería ejercitar la facultad de devolución, «debe guardarse entre pecho y espalda aquellos reparos que en lo íntimo de su conciencia le sugiera el texto aprobado por las Cortes; y allá, cuando la historia haya echado su polvo amarillento sobre las colecciones de la Gaceta y del Diario de Sesiones, cuando los actos presidenciales no puedan tener la resonancia lastimosa que hoy tienen, podrá explicar en sus Memorias, ante el país, por qué promulgó una ley con cuyo texto no estaba conforme... ${ }^{14}$. Y abordando más directamente la pretensión expuesta por el Presidente sobre la tercera vía que había escogido, añadía: «Nosotros no podemos admitir - sirva esto de esclarecimiento para el futuro- que el Presidente de la República tenga otro derecho que aquel estricto que le corresponde por el art. 83 de la Constitución de devolver aquí las leyes que sean objeto de nueva deliberación. Cuando razonés de otro orden disminuyen, apaguen, asfixien o ahoguen los reparos de orden jurídico que al Presidente de la República le susciten la lectura del texto de una ley, el Presidente de la República tiene la sagrada obligación de callarse.... ${ }^{15}$.

El tercer problema consiste en determinar el valor constitucional de la nota presidencial. Gil-Robles, en la discusión parlamentaria de la misma, sostuvo la tesis de que si no quedaba cubierta por el refrendo ministerial debía considerarse formalmente inexistente: «La ley —decía- está en la Gaceta; la ley está promulgada; la ley tiene todos los requisitos para entrar en vigor. ¿Qué el Presidente de la República ha acompañado ese acto de la promulgación de unas cuartillas que expresan un criterio personal, extraordinariamente respetable? Conformes; pero una de dos: ¿forman parte del acto de promulgación? Pues tiene el refrendo del Ministro que la llevó a la Gaceta con el Decreto correspondiente. ¿Se entiende que no forman parte del acto de promulgación? ¿No tiene el refrendo en ese respecto? Pues son un acto, políticamente inexistente y nadie tiene derecho a examinarlo en el Parlamento, porque no hay Gobierno que pueda responder de lo que es inexistente con arreglo a la doctrina constitucional...» ${ }^{16}$. Por su parte, Royo Villanova, algún tiempo

${ }^{14}$ Ibídem, pág. 2526.

15 Ibidem, pág. 2527.

16 Ibidem, págs. 2538-2539. 
después, en sede extraparlamentaria, recogía la tesis de Gil-Robles que reforzaba con el argumento de que la nota presidencial no se había publicado en los Diarios oficiales: «Así como en la práctica forense -escribía- suele decirse que lo que no está en los autos no está en el mundo, para el Parlamento no tiene existencia oficial ningún documento del Gobierno ni del Presidente de la República ni de la Cámara misma que no se haya publicado en el Diario de Sesiones... En una democracia republicana, los documentos que no se publican en la Gaceta no pueden tener eficacia legal, y los que no se publican en el Diario de Sesiones no pueden tener eficacia parlamentaria... ${ }^{17}$. Tales argumentos, desde una perspectiva forma, parecen atinados. Pero, desde una perspectiva realista, quizá resultase exagerado considerar como acto inexistente el que - aparte la controversia parlamentaria - produjo y pudo producir consecuencias políticas muy graves. Por de pronto, provocó una crisis ministerial: el Gobierno Lerroux consideró, con fundamento, que el Presidente de la República le había retirado su confianza y presentó la dimisión. Pero, además, el episodio estuvo a punto de provocar una crisis presidencial: en aquellos días, Casanueva, por encargo de Gil-Robles, visitó a Lerroux para ofrecerle en la primera sesión de Cortes un voto de confianza que significara, al propio tiempo el de censura contra Alcalá-Zamora ${ }^{18}$. Lerroux se negó por dos motivos fundamentales. De una parte, le resultaba muy duro derribar o intentar derribar al primer Presidente de la República. De otra, por el daño que supondría para el régimen y por el ejemplo negativo que se daría al pueblo: «La República - le respondió a Casanueva - no podría vivir sin la armonía y la disciplina de los republicanos y sin la subordinación del pueblo. Ni la armonía, ni la disciplina, ni la subordinación se fomentan ni pueden siquiera mantenerse cuando los representantes y dirigentes dan ejemplo de todo lo contratio y se dedican a destruir las jerarquías...» ${ }^{19}$.

\section{LAS DISOLUCIONES DE LAS CORTES}

El artículo 81 de la Constitución atribuía al Presidente de la República la potestad de disolver las Cortes hasta dos veces como máximo durante su mandato, cuando lo estimase necesario, mediante decreto motivado y acompañando al de disolución el de convocatoria de nuevas elecciones para el plazo máximo de diez días: «En el caso de segunda disolución —añadía- el primer acto de las nuevas Cortes será examinar y resolver. sobre la necesidad del decreto de disolución de las anteriores. El voto desfavorable de la mayoría absoluta de las Cortes llevará aneja la destitución del Presidente». La existencia de este precepto, con sus limitaciones, se justificaba por la necesidad de evitar los abusos que se habían cometido, en materia de disolución, en el régimen monárquico; pero el acierto de los correctivos introducido resultaba muy discuti-

${ }^{17}$ Royo Villanova, La Constitución española de 1931, con glosas jurídicas y apostillas políticas, Valladolid, .1934, págs. 257-258.

${ }_{18}^{18}$ Gil-Robles, No fue posible la paz, págs. 121-122.

19 Lerroux, op. cit., pág. 261. 
ble ${ }^{20}$. Este precepto tuvo aplicación práctica: en abril de 1936, llevó a la destitución de Alcalá-Zamora como Presidente de la República, provocándose, de este modo, una grave crisis constitucional en una situación política y social muy radicalizada que anunciaba ya guerra civil. En todo caso, de aquel artículo y de su aplicación, aquí nos interesa retener un extremo muy concreto: el refrendo de los Decretos de disolución y la conjugación en ellos de la actuación del Jefe del Estado y la del Gobierno. Y en relación a tal extremo, conviene apuntar ya una anomalía inicial: el artículo 81 atribuía el derecho de disolución al Presidente de la República; tal Decreto, como todos los actos de éste, se hallaba sujeto al refrendo ministerial previsto en el artículo 84; pero si el refrendo es un medio de cubrir la responsabilidad presidencial, reemplazándola con la de los ministros, parecía anómalo exigirlo por razón de un acto del que podía derivarse responsabilidad directa del Jefe del Estado concretada en su destitución ${ }^{21}$. El problema se complicó por la pretensión de AlcaláZamora en considerar que la disolución de las Constituyentes no entraba en el cómputo a que se refería el artículo 81; y por la conducta de los Gobiernos que, en 1933 y en 1936, refrendando los respectivos Decretos de disolución, parecían hacer suya la tesis presidencial. El examen conjunto en cada una de las disoluciones puede, seguramente, ayudar a conocer y comprender el complejo de problemas que se plantearon en cada una de aquellas ocasiones; a advertir la dificultad que ofrecía la conjugación de poderes del Jefe del Estado y del Gobierno; y a subrayar la peculiar condición del refrendo en el supuesto del artículo 81 .

\section{La redacción}

El Decreto de disolución de las Cortes Constituyentes, de 9 de octubre de 1933, fue redactado personalmente, con su peculiar estilo, por AlcaláZamora. Este dato concreto fue conocido y comentado, en aquellos tiempos, por tratadistas y políticos. El profesor Bayón, en 1934, refiriéndose a aquel Decreto, escribía: «Es debido al Presidente de la República, señor AlcaláZamora, que lo presentó al Gobierno para que éste lo refrendara, invirtiéndose el procedimiento corriente, según el cual, es el Gabinete quien propone al Jefe del Estado los decretos que éste haya de suscribir, afirmándose así que la facultad disolutoria pertenece de derecho al Presidente y no a su Gobierno.... ${ }^{2}$. Por su parte, Ventosa, en abril del 36, cuando se discutía la destitución de Alcalá-Zamora, afirmaba y recordaba que el Decreto de disolución de octubre del 33, «fue redactado en su preámbulo y en su parte dispositiva, por el señor Presidente de la República.... ${ }^{23}$. En fin, el mismo Alcalá-Zamora, en sus Memorias refiere que asumió la tarea de redactarlo personalmente por varios motivos: «Por ser prerrogativa peculiar del Jefe del Estado, sometido

${ }^{30}$ Sobre el tema, véase Pérez Serrano, La Constitución, págs. 267-268. Véase, también, Bayón y. Chacón, El derecho de disolución del Parlamento, Madrid, 1935.

${ }^{21}$ Sobre el tema, véase Cáceres Crosa, El refrendo ministerial, Madrid, 1934.

${ }^{22}$ Bayón y Chacón, op. cit., pág. 278.

${ }_{23}$ Diario de Sesiones, 7 de abril de 1936, pág. 255. 
personalmente a las consecuencias de su ejercicio, la de disolución de las Cortes; por exigirse constitucionalmente decreto razonado; por los problemas que en tal razonamiento había de tratarse y por espontánea confesión de no estar en condiciones de hacerlo por sí...» el entonces Presidente del Gobierno, Martínez Barrio ${ }^{24}$. El Decreto de disolución, en su exposición preliminar, consignaba como causas de la misma, la realización de la misión que a las Constituyentes correspondía; la trascendencia de la obra consumada que parecía aconsejar una nueva consulta popular; las alteraciones ocurridas respecto del número y efectivos de los partidos; la inexistencia de una mayoría estable; $\mathrm{y}$, por último, la necesidad de buscar en unas elecciones generales una orientación política clara y precisa. Pèro, sobre todo, interesa subrayar aquí que el preámbulo apuntaba ya el tema señalado: el Presidente de la Repúbilca dejaba consignado en él su criterio de que las Constituyentes no contaba a los efectos del cómputo fijado en el artículo 81 de la Constitución ${ }^{25}$.

El Decreto de disolución de las Cortes, de 7 de enero de 1936, fue asimismo redactado personalmente por Alcalá-Zamora. También en este punto los testimonios son varios y autorizados. Por de pronto, Prieto, en los días que se preparaba la destitución de Alcalá-Zamora, lamentó, en el Congreso, que el Presidente de la República hubiera utilizado la exposición de motivos para sostener la afirmación polémica de que la disolución de las Constituyentes no podía entrar en el cómputo de que se ha hecho mención ${ }^{26}$. Por su parte, Portela Valladares, en los mismos días, señaló que si la facultad de disolver las Cortes correspondía al Jefe del Estado, era derecho y deber de éste la redacción y motivación ${ }^{27}$. El fin, el propio Alcalá-Zamora, también en sus Memorias reconoce que después de redactar el Decreto, lo pasó, para su examen detenido y riguroso, a Portela. El Decreto de 7 de enero, escrito en el estilo, siempre inconfundible, de Alcalá, fundaba la disolución de las Cortes en que se había alterado la composición y significado de los partidos que se habían presentado en las elecciones del 33; en la tibieza, lentitud y dificultad de las Cortes para legislar aun en materias económicas y financieras «en que la necesidad apremia y la pasión no ofusca»; en que no había mediado elecciones parciales para Diputados «que en todo lugar y tiempo son signo indicador»; en que los actos de violencia y las prevenciones legales de las autoridadēes habían mantenido prolongada anormalidad para la expresión serena y libre de la opinión-pública. Pero también aquí es necesario subrayar de nuevo que el preámbulo recordaba què ya en el del Decreto del 33 se había indicado que la disolución de las Constituyentes no contaba-a-efectos del artículo 81: «A este criterio — se decía- acompañó el asentimiento de - los partidos que refrendaron tal Decreto y le había precedido el de los que mu-

${ }^{24}$ Alcalá-Zamora, Memorias, 1977, pág. 247.

${ }^{25}$ La redacción del Preámbulo permitía adivinar la pluma que lo escribía. El Socialista, del 10 de octubre de 1933, bajo el título «El Preámbulo del Decreto de disolución», comentaba malévolamente: «No hemos podido evitar leyendo el Preámbulo del Decreto de disolución, un conato de mareo... Es un documento conceptuoso, abogadesco, escrito sin duda, por una persona habituada al galimatías... Góngora, el poeta cordobés, no hubiera sido capaz de ofrecérnoslo más oscuro.»

${ }_{26}$ Diario de Sesiones, 3 de abril de 1936, pág. 11.

27 Diario de Sesiones, 7 de abril de 1937, pág. 259. 
chos antes demandaban aquella disolución, expedita en cuanto no comprometía o gastaba prerrogativa muy reducida. Era necesario, y basta ahora recordar el precedente inmediato de la nueva y distinta disolución que va a acordarse... ${ }^{28}$.

\section{El refrendo}

Alcalá-Zamora redactó el Decreto de disolución en 1933; preparó también el Decreto complementario, muy sucinto, convocando nuevas elecciones; pasó los dos Decretos al Gobierno. «Llevóse Martínez Barrio - escribe aquel en sus Memorias - los originales de los dos Decretos para que los examinara el Gobierno, y afortunadamente para mí fueron los ministros tan minuciosos en el examen del texto, palabra por palabra, que acordaron trasladarse solemnemente desde Gobernación, donde estaban reunidos, a palacio para pedirme con empeño, cual lo obtuvieron, la supresión de ocho palabras, o mejor dicho, siete y un grupo numérico, en el Decreto de convocatoria... ${ }^{29}$. En efecto, esta petición de supresión, por la materia sobre que recaía, revelaba que el Gobierno había estudiado, con el mayor detalle, los términos de aquel Decreto. El Presidente de la República accedió al ruego del Gobierno: «La insistencia de éste - sigue Alcalá-Zamora- sobre extremo tal de redacción probaba con huella indeleble a qué minucioso examen había llegado el Gobierno en el que estaban representados todos los partidos de izquierda republicana burguesa y de qué modo asentían a todo lo demás, entre lo cual, lo más importante y destacado era la afirmación rotunda, extensamente razonada, de que la disolución de las Constituyentes, al no tener éstas plazo legal de duración, no se contaba entre las dos de Cortes ordinarias a que la Constitución limitaba la prerrogativa presidencial. Sobre esto, hubo conformidad unánime, expresa y reflexiva.... ${ }^{30}$. De esta manera, sin perjuicio de la responsabilidad del Presidente de la República, el Gobierno Martínez Barrio - como señalaría luego Ventosa en abril del 36- asumió la responsabilidad legal del refrendo que venía impuesta por el artículo 84 de la Constitución; pero asumió también, con el examen meticuloso del texto - añadía Ventosa-, «una responsabilidad moral por haber prestado su plena conformidad al preámbulo o exposición de motivos del Decreto de disolución de las Cortes...» ${ }^{31}$. Conviene reiterarlo y subrayarlo: el réfrendo prestado por el Gobierno Martínez Barrio adquiría -una-dimēensión adicional y peculiarísima: el Gobierno y los partidós en él representados avalaban la tesis mantenida por - el Presidente de la República, en la exposición de motivos,

El subrayado es nuestro.

29 Alcalá-Zamora, Memorias, pág. 247.

${ }^{30}$ El subrayado es nuestro. En realidad, el tema quedó planteado con claridad; peto sin la amplitud y detención que señala Alcalá-Zamora. Quizá éste exagera por descuido o, al contrario, para poner especialmente de manifiesto la conformidad del Gobierno a la tesis mantenida por aquél.

${ }^{31}$ Diario de Sesiones, 7 de abril de 1936, pág. 255. Ventosa, en ese discuso, reveló o recordó al Congreso el examen y la trayectoria seguido por el Decreto de disolución con perfecto conocimiento de todas las interioridades de tal trayectoria. Su versión coincide esencialmente con la propuesta por Alcalá-Zamora en sus Memorias y que se expone en el texto. 
según la cual la disolución de las Constituyentes no entraba en el cómputo del artículo 81 de la Constitución.

El Decreto de disolución de 7 de enero de 1963 pasó también, como era obligado, a refrendo del Ministerio presidido por Portela; y éste avaló también la tesis, tantas veces mencionada, sostenida por el Jefe del Estado. Más todavía: en este caso, puede afirmarse que el refrendo fue o tuvo que ser éspecialmente consciente por cuanto - al parecer- Alcalá-Zamora, en diciembre del 35, condicionó la entrega del poder a que el Gobierno que se formase aceptase expresamente aquella tesis. En este punto, Miguel Maura, en los días de abrill de 36, afirmó, en sede parlamentaria, que cuando, después de la caída del último Ministerio presidido por Chapaprieta, el Presidente de la República le confió, esporádicamente, la formación de Gobierno, lo hizo con aquella grave y singular imposición: «Cuando yo fui encargado de formar Gobierno - dijo- para disolver las Cortes pasadas, recibí el encargo con las condiciones usuales en esos casos, y una de la condiciones que me impusieron a mí y que impusieron también al señor Portela, era la de que el Gobierno había de tener homogeneidad en determinados problemas, y entre otros, en éste: en el de que los Ministros habían de estar conformes en que la disolución de aquellas Cortes era la primera, porque había que refrendar un Decreto, y ese Decreto, si no estaban conformes en ello los Ministros, podía provocar una crisis...» ${ }^{32}$. Es decir: Alcalá, forzando en este punto la presión constitucional y política, exigía, como garantía previa, a quien formase Gobierno que asumiese su propia interpretación del artículo 81. En todo caso, el Ministerio Portela repasó cuidadosamente la motivación y el contenido del decreto: «Acerca de Portela -escribe Alcalá-Zamora- diré aquí que el texto del Decreto; de que renegó, lo leyó dos veces ante los dos gobiernos por él presididos, y con tal detención que según me dijo hizo resaltar hasta las comas y por encima de todo que se trataba de las primeras Cortes ordinarias y, por tanto, de la primera disolución computable, punto sobre el cual recayó la más absoluta unanimidad de los ministros.... ${ }^{33}$. De esta manera, los partidos republicanos de centro y de izquierda habían avalado, en octubre del 33 , con su refrendo, la tesis del Presidente de la República; los partidos republicanos del centro y de derecha, con su refrendo, en enero del 36, le aportaron nuevo aval: los socialistas y cedistas se mantuvieron, en ambos casos, al margen del mismo y de sus implicaciones.

\section{La retractación}

El Gobierno, con su refrendo, asumía su propia responsabilidad en los términos a que se refería el artículo 84 de la Constitución, sin que, por ello, se eliminase la responsabilidad política del Presidente de la República a que se se refería el artículo 81 . Pero tanto Martínez Barrio como Portela, mediante

${ }^{32}$ Diario de Sesiones, 7 de abril de 1936, pág. 263. Portela nègo la afirmación de Maura; pero resulta difícil imaginar que éste inventase acusación tan grave.

${ }_{33}$ Alcalá-Zamora, Memorias, pág. 361. 
silencios calculados o declaraciones expresas, trataron, luego, de desvirtuar $\mathrm{y}$ aun de suprimir aquella dimensión del refrendo en virtud de la cual habían avalado la tesis de que la disolución de las Constituyentes no debía entrar en el cómputo del artículo 81. Por de pronto, Martínez Barrio. Cuando se discutió y acordó, en abril del 36, la destitución de Alcalá, era Presidente del Congreso; Ventosa recordó, en sede parlamentaria, la actuación que, con sus $\mathrm{Mi}$ nistros, había tenido en octubre del 33, aceptando la teoría del Jefe del Estado; Martínez Barrio no se consideró obligado o no se atrevió a aclarar su conducta y, a lo sumo, dio, en los pasillos, explicaciones de dudosa veracidad. En este punto, Alcalá recuerda que Sánchez-Albornoz, Gordón Ordás y Palomo, Ministros en octubre del 33, olvidando o renegando el asenso prestado en esa fecha, dieron su voto, en abril del 36 , a todos los trámites que llevaron a su destitución: «Pero la máxima y más execreable inconsecuencia —añadela que merecía más dura y despectiva condenación fue la de Martínez Barrio, so pretexto de que su refrendo de aquel decreto no le obligaba a nada, ya que para suplir su preparación personal lo redacté yo. La inconstitucionalidad de la excusa era patente, pero la falsedad también. Cuando se le recordó la prueba plena de su asentimiento que suponía la supresión de aquellas ocho palabras, negó esta circunstancia, faltando a sabiendas y por completo a la verdad.... ${ }^{34}$. De esta manera, Martínez Barrio y alguno de sus Ministros, con su conducta o con su silencio, repudiaron en 1936 la tesis que habían aceptado en 1933; y, de algún modo, fueron contra sus propios actos que no recaían sobre materias secundarias de Derecho privado, sino sobre los temas más graves de Derecho constitucional.

Por su parte, Portela, también de manera ambigua, se desentendió o quiso desentenderse de la dimensión del refrendo que ahora se está examinando. Portela, en el Congreso, en abril del 36, partía de un dato cierto: la redacción y motivación del Decreto de disolución había sido obra personal del Presidente de la República: el Gobierno la había examinado y - con las matizaciones apuntadas- lo había refrendado. Partiendo de esta realidad, Portela añadía: «En ese Decreto hay dos partes: una, aquella en que se motiva o se razona el decreto de disolución, punto éste en el que necesariaméntè quien tiene la iniciativa y la facultad que debe ser respetada en todo momento, es el señor Presidente de la República. Si la facultad es suya, la motivación debe ser suya. Del fondo de la resolución, responde el Gobierno... En ese decreto que se ha leído esta tarde, la parte dispositiva no dice a propuesta del Consejo, sino de acuerdo con la Constitución, con la conformidad del Consejo de Ministros, se disuelven las primeras Cortes ordinarias de la República.... ${ }^{35}$. La argumentación de Portela parecía significar —y así se entendió- que el Decreto de disolución podía disociarse en dos partes: la expositiva, que era obra y responsabilidad del Jefe del Estado; y la dispositiva, de la que se responsabilizaba el Gobierno. Con tal argumentación, Portela pretendía, con cierta desenvoltura constitucional, política y aun ética, anular el aval aportado por su Gobierno a la tesis del Jefe del Estado. Tal pretensión resultaba difícilmente admisible.

${ }^{34}$ Ibidem.

${ }^{35}$ Diario de Sesiones, 7 de abril de 1936, pág. 255. 
En este sentido, Ventosa advertía que no era correcto, a los efectos del refrendo, aceptar aquella distinción: «Un decreto - precisaba- es un conjunto orgánico y en él no se puede separar la exposición de motivos de la parte dispositiva; si no, será de una perfecta incongruencia. La firma aparece al pie del Decreto y, por tanto, cubre con su responsabilidad, acompaña con su responsabilidad, la responsabilidad del señor Presidente de la República...» ${ }^{36}$. Por su parte, Miguel Maura, más exaltadamente, afirmaba que «esta novísima teoría según la cual el Presidente del Consejo o el Ministro que refrenda un Decreto presidencial, no responde más que de la parte dispositiva, es una cosa que se ha cocido en la cabeza del señor Portela Valladares, pero que nadie puede entender...»; y le reprochaba, duramente, que debiéndolo todo al Presidente de la República fuese «a soltar en medio del hemiciclo, como un fardo, no sólo su responsabilidad, sino a la persona que lo ha exaltado y del que es criatura.... ${ }^{37}$.

${ }^{36}$ Diario de Sesiones, 3 de abril de 1936, pág. 21.

${ }^{37}$ Diario de Sesiones, 7 de abril de 1936, pág. 266. Por lo demás, Madariaga, comentando la destitución de Alcalá-Zamora, escribe: «No sale tampoco absuelto como mera víctima el propio Alcalá-Zamora. El fue quien, contra toda objetividad política, y por mera soberbia, declaró que la disolución de las Cortes Constituyentes contaría como una de las dos disoluciones para los fines del artículo 81, evidente contrasentido jurídico que ni él debió haber sentado, ni los demás admitido» (España, 1974, pág. 435). 